\title{
Cannabis-based medicines and pain: a review of potential synergistic and entourage effects
}

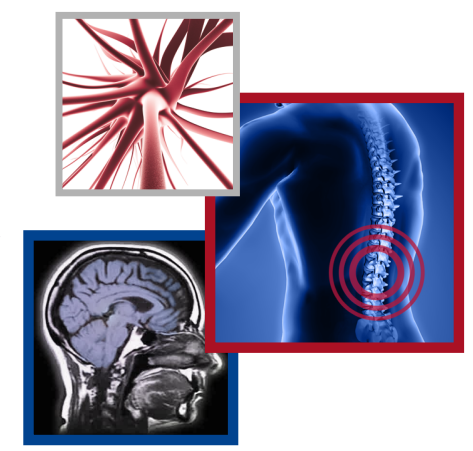

\author{
Uma Anand*,1 (iD), Barbara Pacchetti², Praveen Anand ${ }^{1} \&$ Mikael Hans Sodergren ${ }^{1}$ \\ ${ }^{1}$ Faculty of Medicine, Imperial College London, Hammersmith Hospital, Du Cane Road, London W12 ONN, UK \\ ${ }^{2}$ EMMAC Life Sciences Ltd, 57-61 Mortimer Street, London W1W 8HS, UK \\ *Author for correspondence: u.anand@imperial.ac.uk
}

\section{Practice points}

- Plant-derived and endogenous cannabinoids may act individually, but also in combination(s), to produce analgesia via cannabinoid and other receptors.

- In comparison with pure delta-9 tetrahydrocannabinol (THC), full-spectrum products contain naturally occuring cannabinoids, reported to show improved efficacy or tolerability and patient preference, attributed to combinations of cannabinoid and other components in the cannabis plant.

- While synergy indicates that two or more active compounds may produce an addditive or combined effect greater than their individual separate effects, potentiation of the biological effect of a compound by inactive compounds, in combination, is termed the 'entourage effect'.

- There is supportive data for the synergistic and entourage effects of cannabinoids, but definitive studies in analgesia are still required, from molecular mechanisms to clinical trials.

- Understanding these effects may lead to advances in the treatment of chronic pain.

The recent legalization of medicinal cannabis in several jurisdictions has spurred the development of therapeutic formulations for chronic pain. Unlike pure delta-9-tetrahydrocannabinol (THC), full-spectrum products contain naturally occurring cannabinoids and have been reported to show improved efficacy or tolerability, attributed to synergy between cannabinoids and other components in the cannabis plant. Although 'synergy' indicates that two or more active compounds may produce an additive or combined effect greater than their individual analgesic effect, potentiation of the biological effect of a compound by related but inactive compounds, in combination, was termed the 'entourage effect'. Here, we review current evidence for potential synergistic and entourage effects of cannabinoids in pain relief. However, definitive clinical trials and in vitro functional studies are still required.

Lay abstract: Cannabis-based medicines have been used for millennia, and recent studies have identified their main constituents for pain relief, delta-9-tetrahydrocannabinol and cannabidiol (CBD). However, cannabis contains hundreds of other potentially active compounds, and their combined effects may underlie the reported preference of some patients for cannabinoid extracts, rather than pure delta-9tetrahydrocannabinol. Further, cannabis-based drugs may interact with endocannabinoids, which are produced within the body and are related to the compounds found in cannabis. We have reviewed the evidence for cannabinoids in combination, and with other drugs, for pain relief. Although there is some evidence for an advantage of combinations, basic research and clinical studies are still required.

First draft submitted: 31 December 2020; Accepted for publication: 25 February 2021; Published online: 11 March 2021

Keywords: cannabinoids $\bullet$ entourage effect $\bullet$ neuropathic $\bullet$ pain $\bullet$ terpenoids

\section{Cannabinoids \& their receptors}

Although the cannabis plant (Cannabis sativa L., fam. Cannabaceae) has been used anecdotally for millennia for treating a variety of medical conditions in traditional medicinal practice, more recent evidence-based structured pharmacological studies have identified some of its biological targets and underlying mechanisms of action. Of the 
main ingredients, delta-9-tetrahydrocannabinol (THC) mediates psychoactive and other effects including analgesia, while cannabidiol (CBD) is known not to be psychoactive in terms of inducing euphoria.

Two major endogenous cannabinoids have been identified, anandamide (arachidonoyl ethanolamide) and 2-AraGl (2-arachidonoylglycerol) [1-5]. These endocannabinoids mediate their effects by binding to specific receptors, the $\mathrm{CB}_{1}$ [1] and $\mathrm{CB}_{2}$ receptors [6]. GPR55 is the orphan receptor that is activated by the synthetic cannabinoid ligand CP55940 and has been considered to be the $\mathrm{CB}_{3}$ receptor that couples to $\mathrm{G} \alpha 13$ to mediate the activation of RhoA, Cdc42 and Rac1 (small guanosine triphosphatases [GTPases], ras-related C3 botulinum toxin substrate 1 [Rac1], cell division control protein 42 [Cdc42], and ras homolog gene family, member A [RhoA]). These GTPases regulate signal transduction pathways which influence distinct cellular effects such as cell cycle progression [7].

The cannabinoid receptors are recognized to play an important role in feeding, and studies on the $\mathrm{CB}_{1}$ receptordependent suckling behavior in newborn mice showed that milk intake and survival were impaired in $\mathrm{CB}_{1}$ receptor knockout mice after $\mathrm{CB}_{1}$ receptor antagonist SR141716 administration, though to a lesser extent than wild-type pups. This observation led to the postulate of a third cannabinoid receptor $\mathrm{CB}_{3}$, which may have compensated for the absence of $\mathrm{CB}_{1}$ receptors in the knockout mice [8]. However, further studies are required regarding the localization and role of a $\mathrm{CB}_{3}$ receptor.

Upon agonist binding, cannabinoid receptors $\mathrm{CB}_{1}$ and $\mathrm{CB}_{2}$ activate $\mathrm{G}_{\mathrm{i}}$ which in turn inhibits adenylyl cyclase. Although the $\mathrm{CB}_{1}$ receptors are predominantly expressed in the CNS, they are also localized in sensory neurons of the dorsal root ganglia (DRG) [9-11]. The $\mathrm{CB}_{2}$ receptor is expressed to a greater extent in peripheral tissues mainly in the immune system [6], and in peripheral nerves, where it is upregulated after injury [12-16].

\section{Cannabinoids in pain signaling}

Functional studies in cultured human and rodent sensory neurons identified a role for cannabinoid receptors in peripheral pain signaling; $\mathrm{CB}_{2}$ agonists showed inhibition of capsaicin-induced $\mathrm{Ca}^{2+}$ influx via reduction of cAMP, which led to TRPV1 desensitization [15]. Similarly, other studies identified the $\mathrm{CB}_{2}$ receptor as a target for regulating sensory nerve activity in guinea pig [17] and rat models of acute and chronic pain [18-21], suggesting a modulatory role for cannabinoids by a peripheral mechanism. The increased mRNA expression of the orphan proteins GPR18, GPR55 and $\mathrm{CB}_{2}$ in the spinal cord and DRG of neuropathic rats, and the antinociceptive effect of a dual action compound $\mathrm{N}$-arachidonyl-serotonin (AA-5-HT), which targets fatty acid amide hydrolase (FAAH that metabolizes anandamide), TRPV1, which modulates neuropathic pain via $\mathrm{CB}_{2}$, and GPR18 and GPR55, show the potential for cannabinoid modulation of chronic pain via multiple synergistic targets [22].

Further, there is growing evidence that cannabinoids interact with a variety of receptors besides $\mathrm{CB}_{1}$ and $\mathrm{CB}_{2}$, particularly CBD. These receptors include TRPV1 [23-26], the transient receptor potential vanilloid subtype 1 (TRPV1) receptor, that mediates thermal hyperalgesia by integrating noxious stimuli, such as inflammatory ligands, capsaicin, heat and low $\mathrm{pH}[27,28]$. The endogenous cannabinoid anandamide activates cannabinoid and TRPV1 receptors expressed by subpopulations of DRG neurons and blocks inflammatory hyperalgesia by inhibiting capsaicin-evoked neuropeptide release [29,30].

\section{Entourage effects}

The entourage effect was initially hypothesized by the Mechoulam group to explain their experimental findings, based on studies of endogenous cannabinoids synthesized in various body tissues [31]. Although the term 'synergy' indicates that two or more active compounds may produce an additive or combined effect greater than their individual separate effects, potentiation of the biological effect of a compound by related but inactive compounds, in combination, was termed the 'entourage effect' by the Mechoulam group [31]. Functionally inactive compounds may exert their 'entourage effect' by different mechanisms, such as preventing the degradation of the active ingredient or affecting its binding to a receptor. The endocannabinoid 2-Ara-Gl, identified in the mouse spleen, rat brain and canine gut, was found to be accompanied by several 2-acyl-glycerol esters, of which two major ones are 2-linoleoyl-glycerol (2-lino-Gl) and 2-palmitoyl-glycerol (2-palm-Gl). Although 2-lino-Gl and 2-palm-Gl did not bind to cannabinoid receptors, or inhibit adenylyl cyclase, together these two esters significantly potentiated a tetrad of features including 2-Ara-Gl-mediated inhibition of motor behavior, analgesia on a hot plate, immobility on a ring and hypothermia in mice. 2-Lino-Gl, but not 2-Palm-Gl, significantly inhibited the inactivation of 2-Ara-Gl by neuronal and basophilic cells. These data indicate that the biological activity of 2-Ara-Gl can be increased by related, endogenous 2-acyl-glycerols, which by themselves show no significant activity, but can modulate endogenous cannabinoid activity. Thus, the effect of 2-Ara-Gl was found to be enhanced by the inactive 2-acyl-glycerols that 
prevented its degradation, representing a novel mechanism for molecular regulation of endogenous cannabinoid activity [31]. The biochemical basis of some entourage effects have been partly elucidated, but require further study, especially in pain mechanisms such as desensitization.

The role of cannabinoid and other receptors in mediating entourage effects are likely to be complex, including the postulated cannabinoid receptor $\mathrm{CB}_{3}[7,8]$. Preclinical studies have identified crosstalk between cannabinoid agonists and the noxious pain receptor TRPV1, which is desensitized upon activation [28-30]. The endocannabinoid anandamide was reported to be a full agonist of TRPV1 [23], and the related fatty acid amide, palmitoyl ethanolamide (PEA), potentiated the TRPV1-mediated effects of anandamide and capsaicin, of $\mathrm{Ca}^{2+}$ influx into cells [32].

PEA was also shown to act as an 'entourage' compound in the spinal cord of anesthetized rats by enhancing the hypotensive effects of intrathecally administered sub-effective dose of anandamide, via the $\mathrm{CB}_{1}$ and TRPV1 receptors [33]. In another study, PEA was observed to potentiate the sensory nerve mediated vasodilatory effect of 2-AG in rat arterial mesenteric segments via TRPV1 activation [34]. Similarly, the endogenous fatty acid amide oleamide, was demonstrated to have cannabinoid-like actions by inhibiting FAAH-mediated hydrolysis and potentiating the effects of anandamide, with a role in sleep induction [35]. Thus, there is increasing evidence for different combinations of cannabinoids, for modulation of pain signaling. These effects have been seen clinically and in preclinical models, with plant-derived and endocannabinoids, as described below.

The entourage biological effects of terpenoids on cannabinoids are believed to underlie the preference of some patients for cannabinoid extracts rather than pure THC [36]. The molecular basis of this effect was examined in a study comparing the effects of purified cannabinoids and botanical extracts of cannabis in transfected cells, that found significant inhibitory activity of the botanical extracts compared with the pure cannabinoids at a variety of targets, including the sensory TRPA1, TRPV2 and TRPM8 channels, with a role for target desensitization. However, as these data are derived from transfected cells, further in vivo studies, and in vitro studies with sensory neurons, will be required to confirm the significance of these findings.

Inhibition of the enzymes monoacyl glycerol lipase and diacylglycerol lipase, involved in the synthesis and metabolism of 2-AG from diacylglycerol precursors, have implications both for restricting food intake and producing analgesia, by preventing the metabolism or uptake of endocannabinoids to elevate the levels of these compounds [37].

In a rat model of neuropathic pain, oral treatment with a controlled cannabis extract, containing multiple cannabinoids such as cannabigerol, cannabichromene, cannabidivarin, cannabidiolic acid and other minor components that included terpenes, sterols, triglycerides, alkanes, squalene, tocopherol and carotenoids, when administered in a defined ratio, provided greater antinociceptive efficacy than the single cannabinoid given alone [38].

Other investigators have reported evidence against synergy of some cannabinoid compounds, in particular preclinical models. The entourage effect of plant cannabinoids was examined in a study of six common terpenoids ( $\alpha$-pinene, $\beta$-pinene, $\beta$-caryophyllene, linalool, limonene and $\beta$-myrcene), which showed no modulatory effect on THC-induced hyperpolarization in $\mathrm{CB}_{1}$ or $\mathrm{CB}_{2}$ expressing AtT20 FlpIn cells [39]. In a study of excitotoxic lesions in hippocampal slice cultures, 2-AG and PEA showed neuroprotective effects when applied individually, but not in combination [40]. In a study examining cannabis-mediated analgesia in rats, administration of THC alone produced robust analgesia equivalent to the full cannabis extract, whereas terpenes alone did not [41]. Whether terpenes co-administered with THC can eliminate the undesirable side effects of THC while maintaining the analgesic effects remains to be confirmed. However, as these effects may be dose, tissue or species related, further investigation is warranted.

Another group of cannabinoid receptors, the peroxisome proliferator-activated receptors (PPARs), are reported to mediate synergistic antinociceptive effects with other receptors in the pain pathway. PPAR are ligand-dependent transcription factors that belong to the nuclear hormone superfamily of receptors, widely distributed in the nervous system, and are activated by endogenous compounds derived from saturated and unsaturated fatty acids such as N-PEA and N-oleoylethanolamide. Administration of combined low dose PPAR agonists and opioids in rodent models of inflammatory pain were reported to result in antinociceptive interactions, via an 'entourage' effect involving the opioid receptor, transient receptor potential cation channel subfamily V member 1 (TRPV1) and peroxisome PPAR- $\alpha$ [42].

Cannabinoid combination preparations have shown promising clinical outcomes for treating epilepsy, chemotherapy associated nausea and chronic pain [43,44], with significant dose-related pain relief following treatment with cannabinoids for postoperative pain [45], and improvement in pain relief and quality of sleep in patients with chronic neuropathic pain due to brachial plexus injury [46]. A Phase III placebo-controlled study of Sativex ${ }^{\circledR}(\mathrm{GW}$ Pharma, Cambridge, UK; $\Delta^{9}$-THC and CBD 1:1 ratio combination oromucosal spray) found favorable effects 
for alleviating central neuropathic pain in multiple sclerosis patients [47]. However, clinical and in vitro studies to directly test an entourage effect, as in preclinical behavioral models, are required to elucidate the underlying mechanisms. Entourage effects of cannabinoids related to conditions other than pain relief, such as cancer progression, are outside the scope of this review.

\section{Cannabidiol}

CBD was found to be well tolerated in humans and have anti-convulsive, anti-inflammatory, analgesic and neuroprotective effects [48]. The molecular mechanism of action and therapeutic effects of CBD has been examined in preclinical models of neurological disorders, and clinical trials in children and young adults with Dravet syndrome and Lennox-Gastaut syndrome treated with CBD showed reduced incidence of convulsive seizures [4952]. The efficacy of Sativex was also demonstrated in treating the limb spasticity and pain associated with multiple sclerosis [53].

Although the effects of $\Delta^{9}$-THC are mediated via the $\mathrm{CB}_{1}$ and $\mathrm{CB}_{2}$ cannabinoid receptors [54], other receptor targets for CBD include the orphan G-protein-coupled receptor GPR18, GPR55, TRPV1, PPARs, 5-HT1a receptor and the $\alpha 3$ and $\alpha 1$ glycine receptors [42,55-57].

CBD is advantageous by not being psychoactive in terms of inducing euphoria [48,49], and it increases the tolerability and therapeutic window of $\Delta^{9}$-THC to potentiate its beneficial effects [58]. The CBD content in cannabis flower preparations having a balanced ratio of CBD: $\Delta^{9}-\mathrm{THC}$ alleviates the psychotic symptoms associated with $\Delta^{9}$-THC, compared with preparations with low CBD: $\Delta^{9}-$ THC ratios [59]. Beneficial effects of CBD have also been described in several preclinical models of neurological disorders, especially epilepsy, by a mechanism that is likely to involve neuronal inhibition. CBD by itself has been identified to have anti-inflammatory effects in a bell shaped dose response distribution in a rat model of inflammatory pain. This effect was significantly improved by intraperitoneal injection of the whole plant extract of a Cannabis sativa clone (clone 202) with a high CBD content, to give a correlative dose response with greater effects of analgesia and reduced swelling compared with pure CBD treatment [60].

Clinical effects observed with Sativex led to regulatory approval in several countries including the UK, for alleviating limb stiffness ('spasticity') in patients with multiple sclerosis, with additional benefit observed for the associated pain and urinary incontinence [61]. Sativex was reported to successfully treat neuropathic pain characterized by allodynia, in a randomized, double-blind, placebo-controlled clinical trial [62]. These observations reflect the outcomes of preclinical studies, for example, dose-dependent reduction of allodynia without side effects in a study of THC combined with CBD in mouse models of neuropathic pain [63], and in paclitaxel-induced neuropathy, following treatment with CBD [64]. Quality-controlled medicinal herbal cannabis preparations, when used by patients with chronic non-cancer pain, have a good safety profile [65], with significant reduction in pain intensity [66], and reduced dependence on opioid drugs [67,68].

\section{Terpenoids}

Cannabis contains up to 200 different terpenes, which are lipophilic, and act synergistically with cannabinoids at a variety of targets including G-protein-coupled receptors, muscle and neuron ion channels, enzymes, and second messenger systems, to mediate a variety of therapeutic effects. Whether whole plant cannabis provides additional benefit compared with pure cannabinoids has been debated, although there is increasing evidence that certain cannabis preparations do exhibit differential effects when compared with pure cannabinoids [69]. Cannabis plant strains vary widely in the composition of cannabinoids, terpenes, flavonoids, and other secondary metabolites; these components may work in combination to produce wide variations in benefits, and modulating side effects [69]. Some of the terpenes such as $\alpha$-pinene, $\beta$-myrcene, D-limonene, linalool, $\beta$-caryophyllene, humulene, trans-nerolidol and bisabolol have been analyzed and found to exert a range of effects including anti-inflammatory, analgesic, anxiolytic, antidepressant and sedative in preclinical studies. Knowledge of the individual medicinal properties of the cannabinoids, terpenes and flavonoids is essential to obtain optimal standardized synergistic compositions, and target individual symptoms and/or diseases, including migraine, headache and pain. The concentrations of terpenes have been quantified in 15 cannabis strains; those containing high THC, low CBD and high $\beta$-caryophyllene, followed by myrcene as the predominant terpenes, were reported to be preferred by patients with migraine and other conditions of pain [70]. The effects of individual terpenes in humans and preclinical studies at their physiological concentrations are still required. Among the terpenoids, myrcene was proposed to have analgesic effects by activating TRPV1 [71]. 
Although some of the hundreds of constituents contained in whole plant cannabis extracts have been identified and studied, there is clearly need for further identification of the other components, their combined effects and targets in modulating pain signaling, especially in human studies. This is underscored by the reported preference of many patients for the whole plant extract compared with purified THC, and especially for specific strains, for example, Cannabis sativa strains with mood elevating effects may be better suited for day use, while Cannabis indica strains with sedative effects being preferable for night use. These different subjective effects are likely to arise from variation in the ratios of major and minor cannabinoids, terpenes and other phytochemicals $[70,72,73]$. Information of cannabis-derived compounds other than THC and CBD, regarding their effects on pain in humans, their effective doses, pharmacokinetic profiles and bioavailability, is an important determinant in the development of cannabis-based analgesic therapeutic agents.

\section{'Entourage' effects of cannabinoids linked to other mechanisms of analgesia}

The potential entourage effects can be extended to combinations of cannabinoids with other or overlapping established mechanisms of analgesia. The antinociceptive effects of cannabinoids have been shown to affect the opioid system, and vice versa [74,75]. Cannabinoid agonists enhance the effect of $\mu$-opioid receptor agonists in models of analgesia [76-79], and importantly, reduce dependence on opioid drugs [66,67]. Cannabinoid receptor activation also enhances the analgesic effect of NSAIDs [80-82], so that combinations of cannabinoids with NSAIDs, or cyclo-oxygenase inhibitors like diclofenac [83], can provide effective analgesia while minimizing gastrointestinal (GI) side effects. The synergistic effect of combined cannabis/cannabinoids and opioids has been demonstrated to lower both pain and opioid dose requirements [84].

Thus, there is increasing overall evidence from clinical trials, supporting the beneficial effects of plant derived, endogenous or synthetic cannabinoids for providing pain relief. Pharmacokinetic and pharmacodynamic data are available for THC and CBD, indicating that their lipophilicity prevents oral bioavailability, and that extensive hepatic first-pass metabolism results in lower peak plasma concentration relative to inhalation, with longer delays to reach peak concentration. Inhalational oromucosal delivery bypasses the extensive first-pass metabolism observed following oral cannabinoid administration [85]. Oromucosal preparations are rapidly absorbed via the oral mucosa resulting in higher plasma drug concentrations relative to oral delivery, but reduced when compared with inhalation. Information for the other cannabinoids regarding these important aspects is lacking [86].

\section{Conclusion}

There is a need for further robust assessments of cannabinoids, comparing their single and numerous combination formulations for analgesia. Importantly, definitive clinical trials and in vitro studies are needed to directly test the synergistic and entourage effects of cannabinoids for pain relief, as reported in preclinical behavioral models.

\section{Future perspective}

Recent advances in cannabinoid research for the treatment of pain are promising, with identification of novel endogenous and plant cannabinoids, modes of action and initial combination treatments. Building on these findings, future clinical trials may show that cannabinoids, in combination, provide better efficacy and fewer side effects, and are a favorable option compared with other drugs, particularly opioids. The mechanisms underlying these potential synergistic or entourage effects will be revealed using a range of techniques, in pain signaling or modulating pathways of the peripheral and CNS.

\section{Author contributions}

MH Sodergren and P Anand proposed the review, U Anand drafted the manuscript and all authors contributed to and approved the final manuscript.

Financial \& competing interests disclosure

Funded by EMMAC Life Sciences Ltd. Barbara Pacchetti reports personal fees from EMMAC Life Sciences, outside the submitted work. M Sodergren reports consultancy for Emmac Life Sciences, outside the submitted work. The authors have no other relevant affiliations or financial involvement with any organization or entity with a financial interest in or financial conflict with the subject matter or materials discussed in the manuscript apart from those disclosed.

No writing assistance was utilized in the production of this manuscript. 
Open access

This work is licensed under the Creative Commons Attribution 4.0 License. To view a copy of this license, visit http://creativecommons.org/licenses/by/4.0/

\section{References}

Papers of special note have been highlighted as: $\bullet$ of interest

1. Devane WA, Hanus L, Breuer A et al. Isolation and structure of a brain constituent that binds to the cannabinoid receptor. Science 258(5090), 1946-1949 (1992).

- First identification of an endogenous cannabinoid ligand that explained the effects of cannabinoids.

2. Mechoulam R, Ben-Shabat S, Hanus L et al. Identification of an endogenous 2-monoglyceride, present in canine gut, that binds to cannabinoid receptors. Biochem. Pharmacol. 50(1), 83-90 (1995).

- First identification of co-operativity and modulation in cannabinoids.

3. Sugiura T, Kondo S, Sukagawa A et al. 2-Arachidonoylglycerol: a possible endogenous cannabinoid receptor ligand in brain. Biochem. Biophys. Res. Commun. 215(1), 89-97 (1995).

4. Stella N, Schweitzer P, Piomelli D. A second endogenous cannabinoid that modulates long-term potentiation. Nature 388(6644), 773-777 (1997).

5. Bisogno T, Sepe N, Melck D et al. Biosynthesis, release and degradation of the novel endogenous cannabimimetic metabolite 2-arachidonoylglycerol in mouse neuroblastoma cells. Biochem. J. 322(2), 671-677 (1997).

6. Munro S, Thomas KL, Abushaar M. Molecular characterization of a peripheral receptor for cannabinoids. Nature 365, 61-65 (1993).

- Mechanism to identify peripheral effects of cannabinoids in the immune system.

7. Ryberg E, Larsson N, Sjögren S et al. The orphan receptor GPR55 is a novel cannabinoid receptor. Br. J. Pharmacol. 152(7), 1092-1101 (2007).

8. Hohmann AG, Herkenham M. Localization of central cannabinoid $\mathrm{CB}_{1}$ receptor messenger RNA in neuronal subpopulations of rat dorsal root ganglia: a double-label in situ hybridization study. Neurosci. 90(3), 923-931 (1999).

- Role of cannabinoids in pain signaling in the periphery.

9. Price TJ, Helesic G, Parghi D et al. The neuronal distribution of cannabinoid receptor type 1 in the trigeminal ganglion of the rat. Neurosci. 120(1), 155-162 (2003).

10. Bridges D, Rice ASC, Egertova M et al. Localization of cannabinoid receptor 1 in rat dorsal root ganglion using in situ hybridization and immunohistochemistry. Neurosci. 119, 803-812 (2003).

11. Yiangou Y, Facer P, Durrenberger P et al. COX-2, $\mathrm{CB}_{2}$ and $\mathrm{P} 2 \mathrm{X} 7$-immunoreactivities are increased in activated microglial cells/macrophages of multiple sclerosis and amyotrophic lateral sclerosis spinal cord. BMC Neurol. 6, 12-26 (2006).

12. Stander S, Schmelz M, Metze D et al. Distribution of cannabinoid receptor $1\left(\mathrm{CB}_{1}\right)$ and $2\left(\mathrm{CB}_{2}\right)$ on sensory nerve fibres and adnexal structures in human skin. J. Dermatol. Sci. 38(3), 177-188 (2005).

13. Wotherspoon G, Fox A, McIntyre P et al. Peripheral nerve injury induces cannabinoid receptor 2 protein in rat sensory neurons. Neurosci. 135(1), 235-245 (2005).

14. Anand U, Otto WR, Sanchez-Herrera D et al. Cannabinoid receptor $\mathrm{CB}_{2}$ localisation and agonist-mediated inhibition of capsaicin responses in human sensory neurons. Pain 138(3), 667-680 (2008).

15. Svizenska IH, Brazda V, Klusakova I et al. Bilateral changes of cannabinoid receptor Type 2 protein and mRNA in the dorsal root ganglia of a rat neuropathic pain model. J. Histochem. Cytochem. 61(7), 529-547 (2013).

16. Patel HJ, Birrell MA, Crispino $\mathrm{N}$ et al. Inhibition of guinea-pig and human sensory nerve activity and the cough reflex in guinea-pigs by cannabinoid $\left(\mathrm{CB}_{2}\right)$ receptor activation. Br. J. Pharmacol. 140(2), 261-268 (2003).

17. Ross RA, Coutts AA, McFarlane SM et al. Actions of cannabinoid receptor ligands on rat cultured sensory neurones: implications for antinociception. Neuropharmacol. 40(2), 221-232 (2001).

18. Nackley AG, Zvonok AM, Makriyannis A et al. Activation of cannabinoid $\mathrm{CB}_{2}$ receptors suppresses c-fiber responses and windup in spinal wide dynamic range neurons in the absence and presence of inflammation. J. Neurophysiol. 92(6), 3562-3574 (2004).

19. Elmes SJ, Jhaveri MD, Smart D et al. Cannabinoid $\mathrm{CB}_{2}$ receptor activation inhibits mechanically evoked responses of wide dynamic range dorsal horn neurons in naive rats and in rat models of inflammatory and neuropathic pain. Eur. J. Neurosci. 20(9), 2311-2320 (2004).

20. Sagar DR, Kelly $S$, Millns PJ et al. Inhibitory effects of $\mathrm{CB}_{1}$ and $\mathrm{CB}_{2}$ receptor agonists on responses of DRG neurons and dorsal horn neurons in neuropathic rats. Eur. J. Neurosci. 22(2), 371-379 (2005).

21. Malek N, Kostrzewa M, Makuch W et al. The multiplicity of spinal AA-5-HT antinociceptive action in a rat model of neuropathic pain. Pharmacol. Res. 111, 251-263 (2016).

22. Zygmunt PM, Peterson J, Andersson DA et al. Vanilloid receptors on sensory nerves mediate the vasodilator action of anandamide. Nature 400, 452-457 (1999). 
23. Bisogno T, Hanus L, De Petrocellis L et al. Molecular targets for cannabidiol and its synthetic analogues: effect on vanilloid VR1 receptors and on the cellular uptake and enzymatic hydrolysis of anadamide. Br. J. Pharmacol. 134(4), 845-852 (2001).

24. Iannotti FA, Hill CL, Leo A et al. Nonpsychotropic plant cannabinoids, cannabidivarin (CBDV) and cannabidiol (CBD), activate and desensitize transient receptor potential vanilloid 1 (TRPV1) channels in vitro: potential for the treatment of neuronal hyperexcitability. ACS Chem. Neurosci. 5(11), 1131-1141 (2014).

25. Anand U, Jones B, Korchev Y et al. CBD effects on TRPV1 signaling pathways in cultured DRG neurons. J. Pain Res. 13, 2269-2278 (2020).

26. Caterina MJ, Schumacher MA, Tominaga M et al. The capsaicin receptor: a heat-activated ion channel in the pain pathway. Nature 389, 816-824 (1997).

27. Davis JB, Gray J, Gunthorpe MJ et al. Vanilloid receptor-1 is essential for inflammatory thermal hyperalgesia. Nature 405, 183-187 (2000).

28. Richardson JD, Aanonsen L, Hargreaves KM. Antihyperalgesic effects of spinal cannabinoids. Eur. J. Pharmacol. 345, 145-153 (1998a).

29. Richardson JD, Kilo S, Hargreaves KM. Cannabinoids reduce hyperalgesia and inflammation via interaction with peripheral $\mathrm{CB}_{1}$ receptors. Pain 75, 111-119 (1998b).

30. Ben-Shabat $\mathrm{S}$, Fride $\mathrm{E}$, Sheskin $\mathrm{T}$ et al. An entourage effect: inactive endogenous fatty acid glycerol esters enhance 2-arachidonoyl-glycerol cannabinoid activity. Eur. J. Pharmacol. 353(1), 23-31 (1998).

- First described the entourage effect of co-operativity between active and inactive endocannabinoids in mediating effects.

31. Fride E, Foox A, Rosenberg E et al. Milk intake and survival in newborn cannabinoid CB1 receptor knockout mice: evidence for a “CB3" receptor. Eur. J. Pharmacol. 461, 27-34 (2003).

32. Smart D, Jonsson KO, Vandevoorde $\mathrm{S}$ et al. 'Entourage' effects of $\mathrm{N}$-acylethanolamines at human vanilloid receptors. Comparison of effects upon anandamide-induced vanilloid receptor activation and upon anandamide metabolism. Br. J. Pharmacol. 136(3), 452-458 (2002).

33. Garcia MDC, Adler-Graschinsky E, Celuch SM. Enhancement of the hypotensive effects of intrathecally injected endocannabinoids by the entourage compound palmitoylethanolamide. Eur. J. Pharmacol. 610, 75-80 (2009).

34. Zygmunt PM, Ermund A, Movahed P et al. Monoacylglycerols activate TRPV1 - a link between phospholipase C and TRPV1. PLoS ONE 8(12), e81618 (2013).

35. Mechoulam R, Fride E, Hanu L et al. Anandamide may mediate sleep induction. Nature 389, 25-26 (1997).

36. Notcutt WG, Price M, Chapman G. Clinical experience with nabilone for chronic pain. Pharmaceutical Sci. 3(11), 551-555 (1997).

37. De Petrocellis L, Ligresti A, Morielo AS et al. Effects of cannabinoids and cannabinoid-enriched cannabis extracts on TRP channels and endocannabinoid metabolic enzymes. Br. J. Pharmacol. 163(7), 1479-1494 (2011).

38. Comelli F, Giagnoni G, Bettoni I, Colleoni M, Costa B. Antihyperalgesic effect of a Cannabis Sativa extract in a rat model of neuropathic pain: mechanisms involved. Phytother. Res. 22(8), 1017-1024 (2008).

39. Santiago M, Sachdev S, Arnold JC et al. Absence of Entourage: Terpenoids commonly found in Cannabis sativa do not modulate the functional activity of $\Delta^{9}$-THC at human $\mathrm{CB}_{1}$ and $\mathrm{CB}_{2}$ receptors. Cannabis Cannabinoid Res. 4(3), 165-176 (2019).

40. Hohmann U, Pelzer M, Kleine J et al. Opposite effects of neuroprotective cannabinoids, palmitoylethanolamide, and 2-arachidonoylglycerol on function and morphology of microglia. Front. Neurosci. 13, 1180-1189 (2019).

41. Harris HM, Rousseau MA, Wanas AS et al. Role of cannabinoids and terpenes in Cannabis-mediated analgesia in rats. Cannabis Cannabinoid Res. 4(3), 177-182 (2019).

42. Okine BN, Gaspar JC, Finn DP. PPARs and pain. Br. J. Pharmacol. 176(10), 1421-1442 (2018).

43. Russo EB. Cannabinoids in the management of difficult to treat pain. Ther. Clin. Risk Manag. 4(1), 245-259 (2008).

\section{- Efficacy of cannabinoids in clinical studies.}

44. Anand P, Whiteside G, Fowler CJ et al. Targeting $\mathrm{CB}_{2}$ receptors and the endocannabinoid system for the treatment of pain. Brain Res. Rev. 60(1), 255-266 (2009).

45. Holdcroft A, Maze M, Doré C et al. A multicenter dose-escalation study of the analgesic and adverse effects of an oral cannabis extract (Cannador) for postoperative pain management. Anesthesiology 104(5), 1040-1046 (2006).

46. Berman JS, Symonds C, Birch R. Efficacy of two cannabis based medicinal extracts for relief of central neuropathic pain from brachial plexus avulsion: results of a randomised controlled trial. Pain 112(3), 299-306 (2004).

47. Langford RM, Mares J, Novotna A et al. A double-blind, randomized, placebo-controlled, parallel-group study of THC/CBD oromucosal spray in combination with the existing treatment regimen, in the relief of central neuropathic pain in patients with multiple sclerosis. J. Neurol. 260(4), 984-997 (2013).

48. Pertwee RG. The pharmacology and therapeutic potential of cannabidiol. In: Di Marzo V (Ed.). Cannabinoids Kluwer Academic/Plenum Publishers, NY, USA, 32-83 (2004). 
49. Devinsky O, Cilio MR, Cross $\mathrm{H}$ et al. Cannabidiol: pharmacology and potential therapeutic role in epilepsy and other neuropsychiatric disorders. Epilepsia 55(6), 791-802 (2004).

50. Devinsky O, Marsh E, Friedman D et al. Cannabidiol in patients with treatment-resistant epilepsy: an open-label interventional trial. Lancet Neurol. 15(3), 270-278 (2016).

51. Devinsky O, Patel AD, Thiele EA et al. Randomized, dose-ranging safety trial of cannabidiol in Dravet syndrome. Neurology 90(14), e1204-e1211 (2018a).

52. Szaflarski JP, Bebin EM, Comi AM et al. Long-term safety and treatment effects of cannabidiol in children and adults with treatment-resistant epilepsies: expanded access program results. Epilepsia 59(8), 1540-1548 (2018).

53. Wade DT, Makela P, Robson P et al. Do cannabis-based medicinal extracts have general or specific effects on symptoms in multiple sclerosis? A double-blind, randomized, placebo controlled study on 160 patients. Mult. Scler. 10, 434-441 (2004).

54. Pertwee RG. Pharmacology of cannabinoid $\mathrm{CB}_{1}$ and $\mathrm{CB}_{2}$ receptors. Pharmacol. Ther. 74, 129-180 (1997).

55. Costa B, Giagnoni G, Franke C et al. Vanilloid TRPV1 receptor mediates the antihyperalgesic effect of the nonpsychoactive cannabinoid, cannabidiol, in a rat model of acute inflammation. Br. J. Pharmacol. 143, 247-250 (2004).

56. Patwardhan AM, Jeske NA, Price TJ et al. The cannabinoid WIN 55,212-2 inhibits transient receptor potential vanilloid 1 (TRPV1) and evokes peripheral antihyperalgesia via calcineurin. Proc. Natl Acad. Sci. USA 103(30), 11393-11398 (2006).

57. Lowin T, Schneider M, Pongratz G. Joints for joints: cannabinoids in the treatment of rheumatoid arthritis. Curr. Opin. Rheumatol. 31, 271-278 (2019).

58. Karniol I, Carlini E. Pharmacological interaction between cannabidiol and $\Delta$ 9-tetrahydrocannabinol. Psychopharmacologia 33(1), 53-70 (1973).

59. Schubart CD, Sommer IE, van Gastel WA et al. Cannabis with high cannabidiol content is associated with fewer psychotic experiences. Schizophr. Res. 130(1-3), 216-221 (2011).

60. Gallily R, Yekhtin Z, Hanus LO. Overcoming the bell-shaped dose-response of cannabidiol by using cannabis extract enriched in cannabidiol. Pharmacol. Pharm. 6(2), 75-85 (2015).

61. Pryce G, Baker D. Potential control of multiple sclerosis by cannabis and the endocannabinoid system. CNS Neurol. Disord. Drug Targets 11(5), 624-641 (2012).

62. Nurmikko TJ, Serpell MG, Hoggart B et al. Sativex successfully treats neuropathic pain characterised by allodynia: a randomised, double-blind, placebo-controlled clinical trial. Pain 133(1), 210-220 (2007).

63. Casey SL, Atwal N, Vaughan CW. Cannabis constituent synergy in a mouse neuropathic pain model. Pain 158(12), 2452-2460 (2017).

64. Ward SJ, Ramirez MD, Neelakantan $\mathrm{H}$ et al. Cannabidiol prevents the development of cold and mechanical allodynia in paclitaxel-treated female C57Bl6 mice. Anesth. Analg. 113(4), 947-950 (2011).

65. Ware MA, Wang T, Shapiro S et al. Cannabis for the management of pain: assessment of safety study (COMPASS). J. Pain 16(12), 1233-1242 (2015).

66. Poli P, Crestani F, Salvadori C et al. Medical cannabis in patients with chronic pain: effect on pain relief, pain disability, and psychological aspects. A prospective non randomized single arm clinical trial. Clin. Ther. 169(3), e102-e107 (2018).

67. Sohler NL, Starrels JL, Khalid L et al. Cannabis use is associated with lower odds of prescription opioid analgesic use among HIV-infected individuals with chronic pain. Subst. Use Misuse 53(10), 1602-1607 (2018).

68. Capano A, Weaver R, Burkman E. Evaluation of the effects of CBD hemp extract on opioid use and quality of life indicators in chronic pain patients: a prospective cohort study. Postgrad. Med. 132(1), 56-61 (2020).

69. Russo EB. Taming THC: potential cannabis synergy and phytocannabinoid - terpenoid entourage effects. Br. J. Pharmacol. 163(7), 1344-1364 (2011).

70. Baron EP. Medicinal properties of cannabinoids, terpenes, and flavonoids in Cannabis, and benefits in migraine, headache, and pain: an update on current evidence and Cannabis science. Headache 58(7), 1139-1186 (2018).

- Quantitation of plant cannabinoid constituents and their clinical efficacy.

71. Jansen C, Shimoda LMN, Kawakami JK et al. Myrcene and terpene regulation of TRPV1. Channels 13(1), 344-366 (2019).

72. Fischedick JT, Hazekamp A, Erkelens T et al. Metabolic fingerprinting of Cannabis sativa L., cannabinoids and terpenoids for chemotaxonomic and drug standardization purposes. Phytochemistry 71(17-18), 2058-2073 (2010).

73. Hillig KW. A chemotaxonomic analysis of cannabinoid variation in Cannabis (Cannabacea). Am. J. Bot. 91(6), 966-975 (2004)

74. Ibrahim MM, Porreca F, Lai J et al. $\mathrm{CB}_{2}$ Cannabinoid receptor activation produces antinociception by stimulating peripheral release of endogenous opioids. Proc. Natl Acad. Sci. USA 102(8), 3093-3098 (2005).

75. da Fonseca Pacheco D, Klein A, de Castro Perez A et al. The mu-opioid receptor agonist morphine, but not agonists at delta- or kappa-opioid receptors, induces peripheral antinociception mediated by cannabinoid receptors. Br. J. Pharmacol. 154(5), 1143-1149 (2008). 
76. Reche I, Fuentes JA, Ruiz-Gayo M. Potentiation of delta 9-tetrahydrocannabinol-induced analgesia by morphine in mice: involvement of mu- and kappa-opioid receptors. Eur. J. Pharmacol. 318(1), 11-16 (1996).

77. Yesilyurt O, Dogrul A, Gul H et al. Topical cannabinoid enhances topical morphine antinociception. Pain 105(1-2), 303-308 (2003).

78. Finn DP, Beckett SR, Roe CH et al. Effects of coadministration of cannabinoids and morphine on nociceptive behaviour, brain monoamines and HPA axis activity in a rat model of persistent pain. Eur. J. Neurosci. 19(3), 678-686 (2004).

79. Tham SM, Angus JA, Tudor EM et al. Synergistic and additive interactions of the cannabinoid agonist CP55,940 with mu opioid receptor and alpha2-adrenoceptor agonists in acute pain models in mice. Br. J. Pharmacol. 144(6), 875-884 (2005).

80. Cox ML, Haller VL, Welch SP. Synergy between delta9-tetrahydrocannabinol and morphine in the arthritic rat. Eur. J. Pharmacol. 567(1-2), 125-130 (2007).

81. Guindon J, LoVerme J, De Léan A et al. Synergistic antinociceptive effects of anandamide, an endocannabinoid, and nonsteroidal anti-inflammatory drugs in peripheral tissue: a role for endogenous fatty-acid ethanolamides? Eur. J. Pharmacol. 550(1-3), 68-77 (2006).

82. Ulugöl A, Ozyigit F, Yesilyurt $\mathrm{O}$ et al. The additive antinociceptive interaction between WIN 55,212-2, a cannabinoid agonist, and ketorolac. Anesth. Analg. 102(2), 443-447 (2006).

83. Grim TW, Ghosh S, Hsu KL et al. Combined inhibition of FAAH and COX produces enhanced anti-allodynic effects in mouse neuropathic and inflammatory pain models. Pharmacol. Biochem. Behav. 124, 405-411 (2014).

84. Naidu PS, Booker L, Cravatt BF et al. Synergy between enzyme inhibitors of fatty acid amide hydrolase and cyclooxygenase in visceral nociception. J. Pharmacol. Exp. Ther. 329(1), 48-56 (2009).

85. Pini LA, Guerzoni S, Cainazzo MM et al. Nabilone for the treatment of medication overuse headache: results of a preliminary double-blind, active controlled, randomized trial. J. Headache Pain 13(8), 677-684 (2012).

86. Huestis MA. Pharmacokinetics and metabolism of the plant cannabinoids, delta9-tetrahydrocannabinol, cannabidiol and cannabinol. Handb. Exp. Pharmacol. 168, 657-690 (2005). 
